\title{
A PERSPECTIVA CO-EVOLUCIONÁRIA E SUA APLICAÇÃO À TEORIA DAS ORGANIZAÇÕES
}

\section{A CO-EVOLUTIONARY PERSPECTIVE AND ITS APPLICATION TO THE THEORY OF ORGANIZATIONS}

\section{Flavia Luciane Scherer}

Doutora em Centro de Pós-Graduação e Pesquisas em Administração pela Universidade Federal de Minas Gerais - UFMG

Professora da Universidade Federal de Santa Maria - UFSM

E-mail: flaviascherer @globo.com (Brasil)

\section{Lúcia Rejane da Rosa Gama Madruga}

Doutora em Agronegócios pela Universidade Federal do Rio Grande do Sul - UFRGS

Professora da Universidade Federal de Santa Maria - UFSM

E-mail: lucia.rejane@hotmail.com (Brasil) 


\title{
A PERSPECTIVA CO-EVOLUCIONÁRIA E SUA APLICAÇÃo À TEORIA DAS ORGANIZAÇÕES
}

\section{RESUMO}

Neste artigo são apontados os fundamentos e as possibilidades dos estudos co-evolucionários, os requisitos e as dificuldades para desenvolver tais estudos, bem como são discutidos alguns dos quadros teóricos centrais em teoria das organizações, sob a perspectiva da co-evolução (Lewin e Volberda, 1999). A partir disto, são identificados os possíveis elos que podem ser estabelecidos entre diferentes lentes de estudo, quando integradas em um estudo co-evolucionário. Tais ligações são traçadas tomando-se a análise da teoria institucional (DiMaggio e Powell, 1991; Meyer e Rowan, 1991; Scott, 1995), do enfoque dos custos de transação (Williamson, 1981) e da teoria das relações sociais na ação econômica (Granovetter, 1992). Desta forma, espera-se contribuir para a discussão sobre as possibilidades de maior integração nos estudos organizacionais, quando se chama atenção para a importância de avançar em direção a uma visão mais integradora, que considere as macro dinâmicas sociais e econômicas e seus impactos no nível da firma (efeitos em termos de formato, de identidade, de cultura e de processos de aprendizagem), assim como as relações inversas - da firma para o macro ambiente.

Palavras-chave: Estudos Organizacionais; Co-Evolução; Teoria Organizacional.

\section{A CO-EVOLUTIONARY PERSPECTIVE AND ITS APPLICATION TO THE THEORY OF ORGANIZATIONS}

\begin{abstract}
This article points out the reasons and possibilities of co-evolutionary studies, requirements and problems to develop such studies, as well as discuss some of the theoretical frameworks central to the theory of organizations, from the perspective of co-evolution (Lewin \& Volberda, 1999). We identify the possible links that can be established between different studies, when integrated into a co-evolutionary study. Such links are drawn by taking the analysis of institutional theory (DiMaggio \& Powell, 1991; Meyer \& Rowan, 1991; Scott, 1995), the focus of transaction costs (Williamson, 1981) and the theory of social relations in economic action (Granovetter, 1992). It is expected to contribute to the discussion on the possibilities for greater integration in organizational studies while calling attention to the importance of moving toward being more inclusive. It takes into account the macro economic and social dynamics and their impact on the levels of the firm (in terms of effective size, identity, culture and learning processes) and their inverse relationships from the firm to the macro environment.
\end{abstract}

Keywords: Organizational Studies; Co-Evolution; Organizational Theory.

Revista de Gestão e Projetos - GeP, São Paulo, v. 3, n. 2, p 97-115, mai./ago. 2012. 


\section{INTRODUÇÃO}

O campo dos estudos organizacionais tem passado por sucessivos incrementos oriundos das diferentes perspectivas teóricas sob as quais o pensamento acadêmico tem-se organizado.

Embora, na origem, muitas destas construções teóricas pretendessem solapar o pensamento dominante, o quadro que ora se apresenta permite ampliar as perspectivas em direção a uma visão compreensiva, de múltiplos níveis e com propósito integrador no estudo das organizações. Tal é o desafio com o qual se depara a ciência das organizações, qual seja, compreender os fenômenos organizacionais de forma menos fragmentada, respeitando a complexidade e dinâmica que lhes é inerente. Neste quadro, a co-evolução (Lewin e Volberda, 1999) surgiu como estrutura que possibilita o enriquecimento das pesquisas organizacionais.

A proposta deste artigo é apontar os fundamentos e as possibilidades dos estudos coevolucionários, discutir alguns dos quadros teóricos centrais em teoria das organizações, sob a perspectiva da co-evolução e, a partir disto, identificar os possíveis elos que podem ser estabelecidos entre as diferentes lentes de estudo. O intuito é o de chamar a atenção para a necessidade de estudos mais abrangentes sobre as organizações, os quais possam contar com o uso de convergências entre algumas teorias que podem ser vistas como centrais em tais estudos. Ao mesmo tempo em que se destaca este aspecto, são feitas algumas considerações sobre como realizar os estudos organizacionais através de algumas teorias, sob o enfoque da co-evolução. Em razão dos objetivos pretendidos, optou-se por desenvolver este artigo sob a forma de estudo teórico.

Quanto à estrutura, este estudo está organizado em seções, nas quais o conteúdo teórico é apresentado e discutido. Inicialmente, é feita a explanação sobre os principais aspectos da teoria da co-evolução (Lewin e Volberda, 1999). Na seqüência, passa-se ao estudo de alguns dos paradigmas centrais que atualmente dirigem o pensamento em teoria das organizações e, neste ponto, são feitas as relações com a teoria co-evolucionária. Como paradigmas são discutidos o institucionalismo (DiMaggio e Powell, 1991; Meyer e Rowan, 1991; Scott, 1995), o enfoque dos custos de transação (Williamson, 1981) e a teoria das relações sociais na ação econômica (Granovetter, 1992). Ao final do texto, são apresentadas as conclusões a que se chegou.

Revista de Gestão e Projetos - GeP, São Paulo, v. 3, n. 2, p 97-115, mai./ago. 2012. 


\section{MÉTODO}

A fim de atingir o objetivo central do estudo, procurou-se elaborar um ensaio teórico a partir do qual são apresentados os fundamentos da teoria co-evolucionária, seus requisitos e possibilidades em estudos organizacionais. A partir disso, foram buscados elementos nos principais enfoques teóricos que subsidiam a área para, a partir disso, propor elos entre ambas abordagens, em uma perspectiva co-evolucionária e integradora. Ao final, são apresentadas as conclusões igualmente teóricas - a que se chegou.

\section{A TEORIA DA CO-EVOLUÇÃO, SUAS PROPRIEDADES E SEUS REQUISITOS}

A intencionalidade da ação gerencial tem sido objeto de pesquisa no campo dos estudos organizacionais desde há muito tempo, mas isto não significa que já se tenha alcançado um elevado grau de maturidade ou de congruência entre as teorias que versam sobre o assunto. Ao contrário, Lewin e Volberda (1999) apontam que tal debate parece interminável. A constatação deste quadro impulsionou em certa medida o desenvolvimento de estudos que resultaram na proposta do olhar da co-evolução como nova lente para a pesquisa organizacional.

Em termos da referida intencionalidade, muitos estudos foram desenvolvidos na tentativa de contribuir para o avanço do conhecimento e para a compreensão do seu papel no processo de adaptação organizacional. A extensa literatura sobre processos de adaptação-seleção cobre diversas perspectivas teóricas, mas é inconclusiva sobre o papel da intencionalidade gerencial na adaptação organizacional (Volberda e Lewin, 2003). O Quadro 1 ilustra as principais teorias formadoras do debate adaptação-seleção.

\begin{tabular}{|c|c|c|c|}
\hline $\begin{array}{c}\text { RAÍZES } \\
\text { TEÓRICAS }\end{array}$ & $\begin{array}{c}\text { PARADIGMA } \\
\text { DOMINANTE }\end{array}$ & SELEÇÃO/ADAPTAÇÃO & IMPLICAÇÕES GERENCIAIS \\
\hline Sociologia & Ecologia da População & $\begin{array}{l}\text { Seleção da população e inércia } \\
\text { estrutural }\end{array}$ & $\begin{array}{l}\text { Gestão não faz diferença; novos entrantes } \\
\text { redefinem indústrias; firmas estabelecidas } \\
\text { deveriam focar naquilo que fazem melhor até } \\
\text { que sejam selecionadas para fora. }\end{array}$ \\
\hline
\end{tabular}

Revista de Gestão e Projetos - GeP, São Paulo, v. 3, n. 2, p 97-115, mai./ago. 2012. 


\begin{tabular}{|c|c|c|c|}
\hline & Teorias Institucionais & $\begin{array}{l}\text { Isomorfismo da população baseado } \\
\text { nas normas da indústria e em lógicas } \\
\text { compartilhadas }\end{array}$ & $\begin{array}{l}\text { Empresas estabelecidas deveriam adotar a } \\
\text { estratégia de rápido seguidor }\end{array}$ \\
\hline \multirow{6}{*}{ Economia } & Organização Industrial & 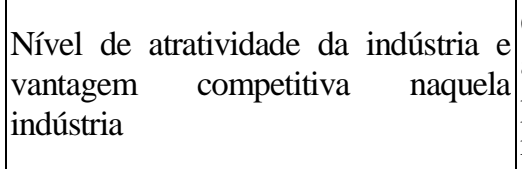 & $\begin{array}{l}\text { Gestores deveriam escolher uma indústria } \\
\text { atrativa; definir a fronteira da performance } \\
\text { para uma estratégia genérica; reduzir a } \\
\text { rivalidade intra-indústria. }\end{array}$ \\
\hline & Custos de Transação & Minimização dos custos de transações & $\begin{array}{l}\text { Gestores deveriam focar em uma relativa } \\
\text { coordenação entre os custos de transacionar } \\
\text { dentro e fora da empresa. }\end{array}$ \\
\hline & $\begin{array}{l}\text { Teoria Comporta-mental } \\
\text { da Firma }\end{array}$ & $\begin{array}{l}\text { Satisfazer múltiplos stakeholders, } \\
\text { inércia estrutural relativa a satisfação, } \\
\text { evitação de incerteza e recessão. }\end{array}$ & $\begin{array}{l}\text { Reestruturação periódica e racionalização. } \\
\text { Exploração requer intenção estratégica para } \\
\text { alocar tempo para inovação. }\end{array}$ \\
\hline & Teorias evolucionárias & $\begin{array}{l}\text { Sucesso reforça melhorias } \\
\text { incrementais e proliferação de rotinas } \\
\text { como origem da inércia }\end{array}$ & 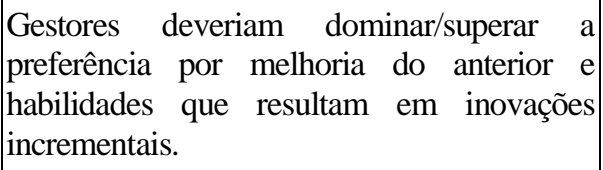 \\
\hline & $\begin{array}{c}\text { Teoria da Firma Baseada } \\
\text { em Recursos }\end{array}$ & $\begin{array}{l}\text { Recursos idiossincráticos são a base } \\
\text { da vantagem competitiva sustentada; } \\
\text { ambigüidade causal ao avaliar as } \\
\text { competências centrais próprias e do } \\
\text { competidor é a origem de } \\
\text { performance sub-ótima. }\end{array}$ & $\begin{array}{l}\text { Gestores deveriam maximizar uma única } \\
\text { competência central, correta ambigüidade } \\
\text { causal em julgar competências centrais } \\
\text { própria e de competidores. }\end{array}$ \\
\hline & $\begin{array}{l}\text { Capacidades Dinâmicas/ } \\
\text { Teoria da Firma Baseada } \\
\text { no Conhecimento }\end{array}$ & $\begin{array}{l}\text { Vantagem competitiva r sustentada } \\
\text { sobre capacidades dinâmica e capital } \\
\text { intelectual. }\end{array}$ & \begin{tabular}{llrrr} 
Gestores deveriam focar & na criação e \\
integração & do & \multicolumn{2}{c}{ conhecimento, } \\
continuadamente & renova & \multicolumn{2}{c}{ base } & de \\
conhecimento. & & &
\end{tabular} \\
\hline \multirow{2}{*}{$\begin{array}{l}\text { Estratégia e } \\
\text { Design da } \\
\text { Organização }\end{array}$} & Teoria Contingencial & $\begin{array}{l}\text { Ambiente origina a variação no } \\
\text { desempenho }\end{array}$ & 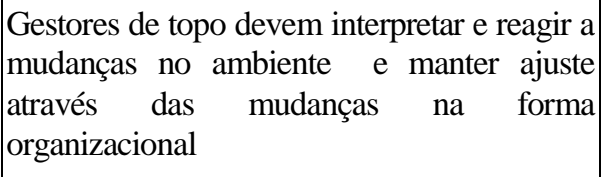 \\
\hline & Escolha Estratégica & $\begin{array}{l}\text { Variação em performance resulta das } \\
\text { mudanças ambientais e do ajuste da } \\
\text { empresa ao ambiente }\end{array}$ & $\begin{array}{l}\text { Gestores deveriam alcançar ajuste dinâmico } \\
\text { através da monitoração e adaptação ao } \\
\text { ambiente }\end{array}$ \\
\hline
\end{tabular}

Revista de Gestão e Projetos - GeP, São Paulo, v. 3, n. 2, p 97-115, mai./ago. 2012. 


\begin{tabular}{|c|c|c|c|}
\hline & $\begin{array}{c}\text { Aprendizagem } \\
\text { Organizacional }\end{array}$ & $\begin{array}{l}\text { Variação em performance resulta das } \\
\text { mudanças ambientais e da habilidade } \\
\text { da organização para adaptar-se através } \\
\text { do aprendizado. }\end{array}$ & $\begin{array}{l}\text { Gestores precisam equilibrar aprendizado de } \\
\text { laço simples e laço duplo. }\end{array}$ \\
\cline { 2 - 4 } & $\begin{array}{c}\text { Ciclo de Vida/ Equilíbrio } \\
\text { Pontuado }\end{array}$ & $\begin{array}{l}\text { Períodos de adaptação e consolidação } \\
\text { são seguidos por períodos de mudança } \\
\text { radical de destruição de competência }\end{array}$ & $\begin{array}{l}\text { Gestores deveriam antecipar mudanças } \\
\text { radicais pela administração da dicotomia } \\
\text { entre inovação radical e incremental }\end{array}$ \\
\hline
\end{tabular}

Quadro 1- Teorias Formadoras do Discurso Seleção-Adaptação.

Fonte: Adaptado de Lewin e Volberda (1999).

Para Lewin e Volberda (1999), é preciso observar que o progresso no campo exige a combinação e a recombinação de múltiplas lentes ao invés da fragmentação crescente - e este é o cerne da teoria coevolucionária. É preciso considerar os resultados conjuntos da adaptação gerencial e da seleção ambiental, ao invés de um ou de outro. Acrescentam, ainda, que a adaptação e a seleção não são forças totalmente opostas; ao contrário, são fundamentalmente inter-relacionadas. O propósito, então, reside em focar em como firmas co-evoluem umas com as outras e com um ambiente organizacional mutável. Quanto ao potencial da co-evolução, Lewin e Volberda (1999) afirmam que ela permite integrar a evolução das organizações nos níveis macro e micro em uma estrutura unificada e incorporar múltiplos níveis de análise, bem como efeitos contingenciais, o que leva a idéias, a teorias, a métodos empíricos e à compreensão das novas formas organizacionais.

A abordagem da co-evolução pretende, portanto, possibilitar a realização de estudos cujo foco esteja no exame das questões sobre como as organizações, de um lado, influenciam sistematicamente seus ambientes e como os ambientes organizacionais, do outro lado, exercem influência sobre elas. A Figura 1, a seguir, demonstra as relações existentes entre indústria, firma e instituições sob uma perspectiva coevolucionária.

Para que seja possível avaliar as possibilidades de aplicação da co-evolução no estudo das organizações, assim como considerar a existência de relações e/ou complementaridades com algumas das perspectivas teóricas que dominam o campo, faz-se necessário descrever as propriedades da co-evolução, conforme sugerido por Lewin e Volberda (1999). As propriedades essenciais da co-evolução são as seguintes:

Revista de Gestão e Projetos - GeP, São Paulo, v. 3, n. 2, p 97-115, mai./ago. 2012. 
- Multiníveis: sob o enfoque da pesquisa co-evolucionária, os efeitos ambientais sobre as organizações são entendidos em múltiplos níveis, tanto na dimensão intrafirma (micro coevolução) como na dimensão entre firmas (macro co-evolução).

- Causalidades multidirecionais: esta propriedade consiste em reconhecer que as organizações e suas partes não evoluem meramente, mas sim co-evoluem umas com as outras e também com o mutável ambiente organizacional. Desta forma, as mudanças podem ocorrer pelas interações mútuas diretas e pelo feedback do resto do sistema.

Figura 1 - Co-evolução da firma, sua indústria e ambiente

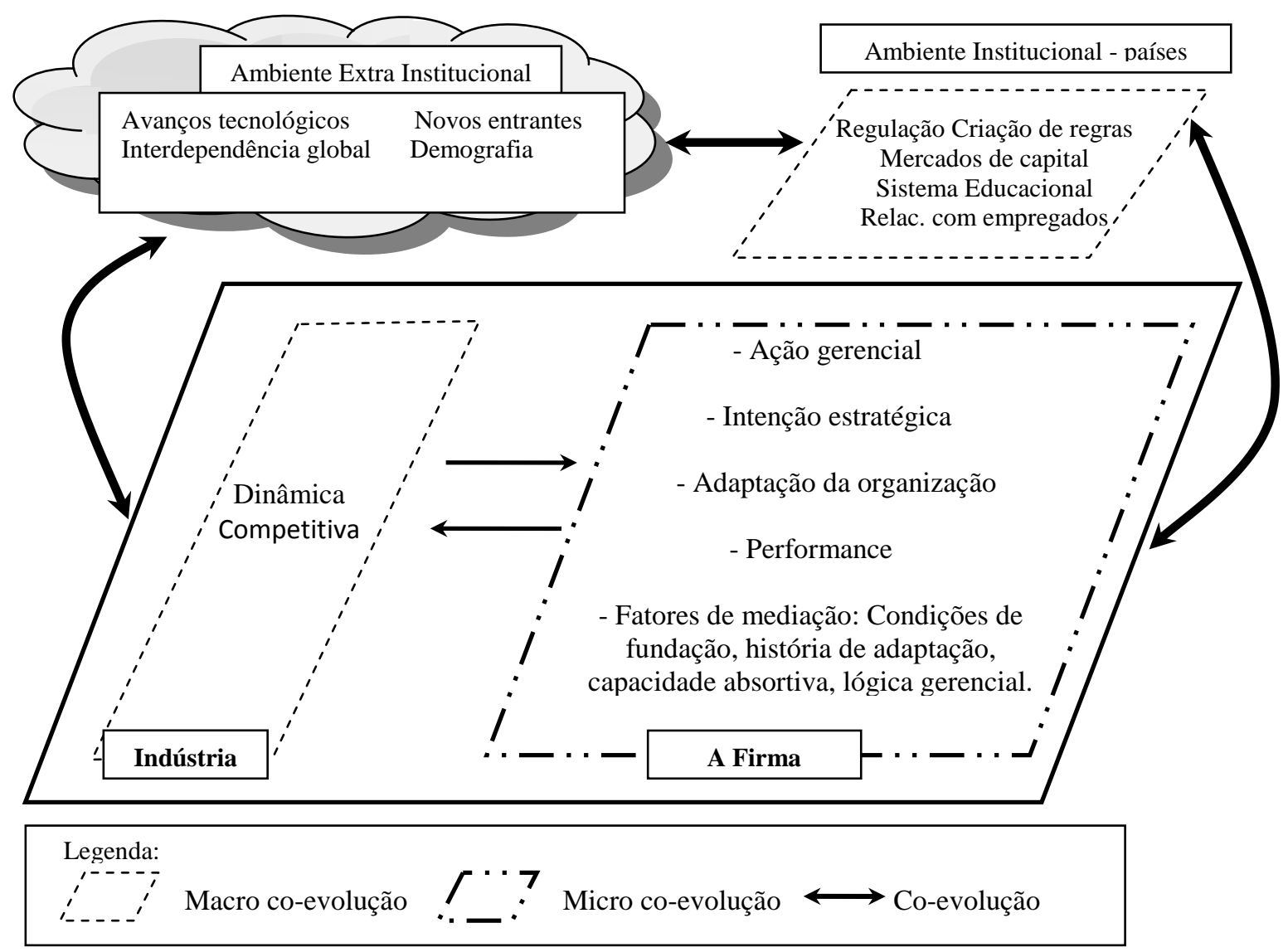

Fonte: Adaptada de LEWIN, Arie Y., LONG, Chris P. e CARROLL, Timothy N. (1999).

- Não-linearidade: o enfoque co-evolucionário exige uma perspectiva de análise não-linear, que estude as mudanças ocorridas nas organizações não somente a partir das interações diretas entre seus pares, mas também pelo feedback indireto do resto do sistema.

Revista de Gestão e Projetos - GeP, São Paulo, v. 3, n. 2, p 97-115, mai./ago. 2012. 
- Feedback positivo: os estudos co-evolucionários entendem que as interações recursivas resultam em interdependências e na causalidade circular. Significa dizer que cada organização influencia outra e, por sua vez, é influenciada pelo comportamento desta outra. Nesta perspectiva de feedback de interação mútua, a visão unidirecional de relacionamento de causa-efeito dá lugar à visão recursiva bidirecional de causalidade mútua, em outras palavras, uma organização não somente responde (efeito) a uma outra organização (causa) como também pode causar uma reação (efeito) nela e isto acontece com todas as organizações que estão interagindo no sistema, seja de forma direta ou não. Daí a idéia de causalidade circular.

- Dependência histórica ou dependência da trajetória: na perspectiva da co-evolução, a adaptação da organização, em um processo co-evolucionário, depende da sua trajetória ou da sua história. Desta forma, para realizar estudos co-evolucionários, é preciso conhecer a história da organização desde a sua criação até o momento atual e, tão importante quanto, deve-se considerar que as organizações pertencentes a uma determinada população se adaptam de formas variadas, como reflexo da heterogeneidade na referida população em momentos temporais anteriores ou devido a um conjunto de condições externas distintas.

Considerando tais propriedades, Lewin e Volberda (1999) alertam que, para realizar o potencial de servir como estrutura unificada para pesquisa sobre estratégia e em estudos organizacionais e para reinterpretar, remodelar e redirecionar o discurso de seleção-adaptação, a coevolução depende de avanços teóricos tanto quanto de dramáticos acréscimos em pesquisa empírica sobre sistemas co-evolucionários. O desenvolvimento de pesquisa empírica sob a abordagem coevolucionária requer métodos longitudinais de análise e dados em séries temporais. Para os autores, pesquisas longitudinais ainda estão longe de se tornarem a norma e irão requerer um arsenal mais rico de métodos e técnicas, além dos já tradicionais. Os desafios metodológicos, portanto, continuam a colocar penosos obstáculos para a pesquisa co-evolucionária empírica.

Além disto, questões relativas à medida e à acessibilidade a apropriados dados temporais também apresentam novos desafios, em particular o uso de taxas de mudança e medidas de velocidade. Para Lewin e Volberda (1999), os esforços para a criação de bases de dados ainda são incipientes e as dificuldades metodológicas fazem com que estudos que integram diversas perspectivas em uma base de séries temporais sejam rara exceção, pois a sequência requerida de dados não está prontamente disponível.

Revista de Gestão e Projetos - GeP, São Paulo, v. 3, n. 2, p 97-115, mai./ago. 2012. 
Com a apresentação das propriedades da co-evolução, dos requisitos e desafios para a pesquisa coevolucionária, foi fornecido um panorama geral a respeito de seus principais elementos. Uma vez descrita a essência da perspectiva co-evolucionária, a próxima etapa consiste em trabalhar as suas relações com outras lentes de estudo e discutir as possibilidades de sua aplicação em pesquisas organizacionais, cujos pressupostos estejam em diferentes perspectivas teóricas, complementares ou não. É o que é realizado na próxima seção.

\section{AS TEORIAS ORGANIZACIONAIS, SUAS CONVERGÊNCIAS E SUAS POSSIBILIDADES EM ESTUDOS CO-EVOLUCIONÁRIOS}

Nesta seção, serão apresentados - de modo sumário - alguns dos principais elementos de paradigmas que atualmente conduzem os estudos em teoria organizacional, para, a partir disto, estabelecer as possíveis relações entre ambos e a co-evolução.

\subsection{A TEORIA INSTITUCIONAL}

O primeiro paradigma a ser analisado diz respeito ao Institucionalismo (Meyer e Rowan 1991; DiMaggio e Powell, 1991; e Scott, 1995), cujo enfoque central é a visão de que campos organizacionais altamente estruturados (ou institucionalizados) provêm um contexto no qual esforços individuais para lidar de forma racional com incerteza e limitações levam, geralmente, à homogeneidade na estrutura, na cultura e na produção.

Um determinado campo organizacional é composto por todas as organizações que constituem uma área reconhecida de vida organizacional, como fornecedores-chave, consumidores de matérias-primas e de produtos, agências reguladoras e outras organizações que oferecem produtos ou serviços similares (DiMaggio e Powell, 1991, p.64). Dentro dos campos, as organizações tendem a se assimilar por conta do isomorfismo, o qual pode ser definido como um processo restritivo que força uma unidade na população a se equiparar com as outras unidades que estão sob o mesmo conjunto de condições ambientais (DiMaggio e Powell, 1991, p.66). O isomorfismo é referido pelos autores como o conceito que melhor captura o processo de homogeneização das organizações, as quais apresentam três tipos diferentes de tal processo nos seus campos organizacionais: (1) o isomorfismo coercitivo; (2) o isomorfismo mimético; e (3) o isomorfismo normativo.

Revista de Gestão e Projetos - GeP, São Paulo, v. 3, n. 2, p 97-115, mai./ago. 2012. 
No primeiro caso, o do isomorfismo coercitivo, a homogeneidade é resultante das pressões formais e das pressões informais que são exercidas sobre as organizações por outras organizações das quais elas são dependentes e também por expectativas culturais da sociedade dentro da qual elas funcionam (DiMaggio e Powell, 1991, p.67). Tais pressões configuram-se pela força, pela persuasão ou por convites para juntar-se à coalizão e, em alguns casos, a mudança organizacional pode ser uma resposta direta aos mandatos governamentais na forma de leis, de regulamentos, ou outros instrumentos de coerção. Para os referidos autores, os Estados dominam muitas arenas da vida social, nas quais as organizações são homogêneas dentro de dados domínios e organizadas em torno de rituais de conformidade para com as instituições.

Em relação ao isomorfismo mimético, ele decorre da imitação de práticas, o que é típico de situações de incerteza, como por exemplo, uma nova tecnologia que ainda é pouco entendida, metas/objetivos que são ambíguos ou a incerteza simbólica criada pelo ambiente (DiMaggio e Powell, 1991, p.69). Entram aí as práticas como o benchmarking e os círculos de controle de qualidade do Japão que foram amplamente copiados.

Considerando o ambiente de incerteza, os autores argumentam que as organizações tendem a modelar-se depois que outras organizações que são similares e fazem parte do seu campo organizacional são percebidas por elas como sendo mais legítimas ou bem sucedidas. Como destacam DiMaggio e Powell (1991, p.70), a onipresença de certos tipos de arranjos estruturais é mais creditada à universalidade dos processos miméticos do que a qualquer evidência concreta de que os modelos adotados garantam eficiência

O terceiro tipo de isomorfismo, o normativo, é determinado pela profissionalização dos indivíduos integrantes das organizações. DiMaggio e Powell (1991, p.70) destacam que os membros de uma ocupação definem as condições e métodos do seu trabalho para estabelecer uma base cognitiva e legitimação para sua autonomia ocupacional.

Resumindo os três processos isomórficos, os autores destacam que cada um deles pode ocorrer mesmo na ausência de evidências de que aumentem a eficiência organizacional interna e de que as similaridades podem tornar mais fáceis as transações com outras organizações.

Nesta perspectiva, faz-se necessária a compreensão de que, em sociedades modernas, as estruturas da organização formal emergem em contextos altamente institucionalizados. Com isso, as organizações são levadas a incorporar as práticas e os procedimentos definidos pelos principais conceitos racionalizados sobre trabalho organizacional, já institucionalizados na sociedade. Desta forma, tais organizações refletem dramaticamente os mitos de seus ambientes institucionais, ao invés de demandas de suas atividades de

Revista de Gestão e Projetos - GeP, São Paulo, v. 3, n. 2, p 97-115, mai./ago. 2012. 
trabalho (Meyer e Rowan, 1991). Assim, é o campo organizacional ou o ambiente institucional que preocupa os autores orientados pelo Institucionalismo, na medida em que ele incide sobre as organizações, ou seja, é o nível macro que é posto em evidência e ganha primazia em seus estudos.

Com tal quadro teórico como orientação, é possível verificar que, em termos de suas propriedades, a co-evolução parece não entrar em divergências com o institucionalismo; ou seja, não há incompatibilidade fundamental entre ambas as perspectivas. Ao contrário há, em grande medida, complementaridade, uma vez que Lewin e Volberda (1999) ressaltam a importância de que os estudos coevolucionários sejam realizados sob o prisma de múltiplos níveis de análise incluindo as dimensões macro (firmas existentes em um contexto competitivo) e micro (contexto intrafirma).

O institucionalismo se debruça com maior ênfase sobre o estudo das relações no nível macro (instituições) o que permite, portanto, que as suas orientações teóricas sejam observadas quando da análise das relações macro co-evolucionárias.

Outro ponto de convergência é encontrado nos requisitos para a pesquisa co-evolucionária definidos por Lewin e Volberda (1999) -, e que dão conta de que é necessário incorporar ao estudo mudanças no nível de diferentes sistemas institucionais, o que torna imprescindível o "olhar" do institucionalismo, especialmente no nível macro de estudos co-evolucionários. No que tange às demais propriedades da co-evolução - causalidades multidirecionais, não-linearidade, feedback positivo e dependência histórica ou da trajetória - vê-se, também, grande afinidade com a perspectiva do institucionalismo.

De maneira geral, em relação às propriedades acima mencionadas, pode-se afirmar que, embora o institucionalismo coloque o nível macro como foco central de análise, ao passo que a co-evolução proponha estudos de múltiplos níveis, é possível e oportuno desenvolver estudos co-evolucionários tendo a teoria institucional como base para a compreensão das relações da sociedade (e suas instituições) com as firmas que compõem um dado campo organizacional. Assim, será possível compreender como o ambiente (que apresenta certo grau de institucionalização) e as organizações - que nele se encontram - coevoluíram, sob uma perspectiva longitudinal de estudo, enfocando os múltiplos níveis de influências mútuas.

Aspectos convergentes e pontos em comum também são encontrados quando se analisa o enfoque dos custos de transação sob a perspectiva da co-evolução. Tais aspectos são descritos a seguir.

Revista de Gestão e Projetos - GeP, São Paulo, v. 3, n. 2, p 97-115, mai./ago. 2012. 


\subsection{O ENFOQUE DOS CUSTOS DE TRANSAÇÃO}

O segundo paradigma a ser avaliado é encontrado no campo da abordagem econômica, no enfoque dos Custos de Transação - tornado clássico pelos estudos de Williamson (1981) - e que traz, em sua origem, a decisiva influência dos estudos de Coase (1937).

Os estudos organizacionais desenvolvidos à luz deste paradigma colocam as transações como unidades básicas de análise e sustentam que a compreensão da economia dos custos de transação é central para o estudo das organizações (Williamson, 1981). Tais transações podem ocorrer em duas formas alternativas de estruturas de governança (mercados e hierarquias), cuja escolha por uma forma particular está condicionada à possibilidade de minimizar os custos de transação, superar a racionalidade limitada e reduzir o oportunismo dos agentes econômicos. É pertinente destacar que, para Williamson (1981, p.552), uma transação ocorre quando um bem ou serviço é transferido através de uma interface tecnologicamente separável, onde um estágio de atividade termina e o outro começa. $\mathrm{O}$ autor destaca que, com uma interface

que trabalhe bem, a transferência ocorre harmoniosamente. É possível comparar os custos de transação com a fricção de uma máquina, pois se as partes estão lubrificadas e a máquina trabalha bem, não haverá perda de energia. Na perspectiva dos custos de transação, significa dizer que não há espaço para desentendimentos e conflitos que levem a atrasos, rompimentos ou outras disfunções, se as partes que transacionam operam em harmonia.

De acordo com Williamson (1981), tal harmonia dependerá da estrutura de governança escolhida e está relacionada ao controle do oportunismo - admitido por ele como sendo típico do comportamento humano no ambiente de mercado (Williamson, 1975) - e à racionalidade limitada (Simon, 1948).

Em relação aos níveis de análise aos quais é aplicada a teoria dos custos de transação, verifica-se que são três: o primeiro diz respeito à estrutura geral do empreendimento; o segundo - nível médio - foca nas partes operacionais e questiona quais atividades deveriam ser desenvolvidas dentro da empresa e quais deveriam ser feitas no mercado; e o terceiro nível ocupa-se de entender o modo pelo qual os ativos humanos estão organizados (Williamson, 1981).

No decorrer da evolução dos estudos organizacionais, a abordagem dos custos de transação recebeu críticas como as de Granovetter (1992), as de Powell (1991) e as de Reed (1999), as quais apontam, principalmente, para a inabilidade da perspectiva dicotômica de mercados e hierarquias em dar respostas às vastas possibilidades de estruturas alternativas de governança e para a ausência de qualquer tentativa de abordar a questão do poder social e da intervenção humana, em termos das lutas pelo poder e das formas de dominação.

Revista de Gestão e Projetos - GeP, São Paulo, v. 3, n. 2, p 97-115, mai./ago. 2012. 
Para Reed (1999, p.74), por exemplo, a forma pela qual esta teoria vê a organização é totalmente compatível com um contexto político e ideológico dominado por teorias neoliberais de organização e de controle da sociedade, “que elevam as 'forças impessoais do mercado' à categoria analítica de universalidades ontológicas dominando as chances individuais e coletivas de sobrevivência”.

Após estas colocações - que foram feitas com o intuito de esclarecer a natureza contestatória da teoria dos custos de transação - pode-se, então, proceder à análise das relações entre o enfoque dos custos de transação e a co-evolução.

Considerando os aspectos ora destacados, parece claro que a teoria dos custos de transação concorre para a compreensão dos fenômenos organizacionais fazendo uso das transações como unidade de análise no nível micro - principalmente - e no nível médio, quando estuda as transações que são feitas fora do empreendimento, através de agentes estabelecidos no mercado. Comparando-a à perspectiva coevolucionária, não é possível afirmar que ambas sejam mutuamente incompatíveis. O mais apropriado seria - talvez - vê-las como complementares, à medida que a co-evolução pode ampliar expressivamente a abordagem de Williamson (1981) e ter-se-ia, desta forma, a co-evolução como categoria abarcante e os custos de transação como categoria abarcada.

Em um estudo co-evolucionário, quando da análise da dimensão intrafirma (micro), pode-se incluir as transações como uma das categorias de estudo, procurando com isto integrar tais perspectivas, ao passo que se evita - em alguma medida - a tendência de fragmentação dos estudos organizacionais. Isto acontece por que é possível lançar mão da análise de aspectos mais abrangentes dos fenômenos organizacionais, como é o caso das transações. A análise das transações realizadas no mercado (extrafirma) também pode ser estudada sob um enfoque co-evolucionário bastando, para isso, que sejam observados os requisitos para a pesquisa, anteriormente apresentados.

Outra possibilidade está em verificar como a teoria dos custos de transação pode contribuir para explicar as escolhas por particulares estruturas de governança, feitas por uma determinada organização ao longo de sua trajetória. Sob sua lente, estas escolhas visam alcançar custos eficientes - ou seja, o critério último de decisão é o econômico. Agregar a esta perspectiva outras formas de entender o mesmo processo é desafio oportuno e relevante para os estudos organizacionais, à medida que permite analisar um mesmo fenômeno por meio de lentes distintas, verificando, por último, quais são as suas complementaridades e exclusões - o que pode levar a um conhecimento mais integrado e crítico.

É propondo esta integração que Granovetter (1992) apresenta a teoria das relações sociais na ação econômica como forma de complementar os estudos de Williamson (1981). A seguir são destacados os principais pontos de tal teoria e, como foi realizado neste tópico e no anterior, é feita a análise sob a

Revista de Gestão e Projetos - GeP, São Paulo, v. 3, n. 2, p 97-115, mai./ago. 2012. 
perspectiva da co-evolução.

\subsection{A TEORIA DAS RELAÇÕES SOCIAIS NA AÇÃO ECONÔMICA}

A terceira perspectiva teórica a ser estudada remete à questão das Relações Sociais na Ação Econômica. Para discuti-la sob a luz da co-evolução, a abordagem sociológica de Granovetter (1992) será mencionada e dela serão destacados os argumentos centrais.

Ao tratar da ação econômica e da estrutura social, Granovetter (1992) aponta que as transações de todos os tipos são abundantes de conexões sociais e ele entende que é um grave engano analisar as instituições independentemente do comportamento humano. Com este argumento principal, a preocupação do autor recai sobre a premissa de que o comportamento econômico e também as instituições estão profundamente impregnados de relações sociais e destaca que entender como as últimas afetam as primeiras é uma das questões clássicas da teoria social.

Para demonstrar a força de seu argumento, Granovetter (1992) propõe-se a utilizá-lo para responder à questão: "quais transações na sociedade capitalista moderna são levadas ao mercado, e quais ocorrem dentro de firmas hierarquicamente organizadas?" Esta questão, para o autor, tornou-se importante no campo organizacional desde os estudos de Williamson (1981), para quem a resposta à pergunta está na avaliação econômica, com privilégio para a estrutura que permita custos mais eficientes. Para Granovetter (1992), as relações sociais - antes dos arranjos institucionais e da moralidade generalizada - são as principais responsáveis pela produção de confiança na vida econômica. Em oposição a Williamson (1981), o autor aponta que, para trazer ordem para a vida econômica, as relações sociais entre firmas são mais importantes do que a autoridade existente dentro delas.

Ao deter-se sobre o problema de confiança e desonestidade - que é significativo para Williamson (1981) -, Granovetter conclui que, por ambas serem aspectos sociais da teoria de custos de transação, a análise sociológica seria a mais apropriada para estudá-las e tal é o seu propósito ao trazer as relações sociais ao centro da discussão. Ou seja, para Granovetter, a questão das transações (com seus problemas de desconfiança e desonestidade), não pode ser olhada apenas sob a ótica da economia - como fez Williamson (1981) -, mas é necessário e central discutir esta questão sob a perspectiva da sociologia, o que deverá, por conseguinte, alçá-la à posição prioritária nos estudos sobre a ação econômica.

Para Granovetter (1992), é crucial perceber que a confiança e a honestidade decorrem muito mais do modo como as relações sociais são construídas do que das estruturas formais presentes nas hierarquias ou mesmo dos contratos que regulam transações, como argumenta Williamson (1981). Ao focar as

Revista de Gestão e Projetos - GeP, São Paulo, v. 3, n. 2, p 97-115, mai./ago. 2012. 
relações sociais das quais a ação econômica está profundamente impregnada, Granovetter (1992) explica que é a compreensão delas que permitirá estabelecer os adequados elos entre as teorias de níveis macro e micro. Ou seja, o estudo das relações sociais permite ampliar a compreensão dos aspectos mais amplos que levaram os sistemas a apresentar as características sócio-culturais em um dado momento, além de melhor informar a análise das relações no nível micro.

Apresentados tais argumentos, é possível avaliar que a lente das relações sociais - com suas questões de confiança e honestidade - é bastante coerente e complementar aos estudos co-evolucionários. $\mathrm{O}$ argumento de Granovetter vai ao encontro das propriedades da co-evolução, como: dependência histórica da adaptação, causalidades multidirecionais e feedback positivo (interações mútuas estão presentes no construto de relações sociais). Assim, pode-se avaliar que, em um estudo co-evolucionário que pretenda compreender padrões organizacionais de adaptação e seleção em uma perspectiva longitudinal, as relações sociais podem ser fator de análise, uma vez que permitem adicionar a lente da sociologia ao campo organizacional, seja nos níveis macro, meso ou micro, pois a ação econômica está embebida de tais relações.

A perspectiva co-evolucionária permite analisar como os relacionamentos sociais evoluíram ao longo da trajetória da empresa, do setor e da sociedade, como influenciaram na configuração das instituições e como foram por elas influenciadas, como serviram como fontes de confiança, enfim, como atuaram na configuração do fenômeno organizacional. Com isto, entende-se que ambas as abordagens podem ser combinadas em perspectivas mais abrangentes nos estudos organizacionais, uma vez que a interação mostra-se mútua e recursiva.

Com a discussão deste tópico, concluiu-se a etapa de avaliação de possíveis relacionamentos entre co-evolução e outras perspectivas teóricas. Apesar de sucinta, acredita-se que tal análise permitiu destacar alguns dos pontos de contato ou interseção, conforme Reed (1999), entre ambas abordagens, deixando ao leitor a possibilidade de explorar outros mais que julgue oportunos.

\section{CONSIDERAÇÕES FINAIS}

Ao término deste estudo, espera-se ter conseguido demonstrar que, ao invés de díspares, as abordagens destacadas apresentam diversas complementaridades e identidades, as quais podem ser exploradas sob uma perspectiva integradora, como a que é proposta pela co-evolução.

Revista de Gestão e Projetos - GeP, São Paulo, v. 3, n. 2, p 97-115, mai./ago. 2012. 
Além das teorias apresentadas, pesquisas recentes dão reforço adicional à perspectiva de Lewin e Volberda (1999), e exemplo disto é que a dinâmica da adaptação organizacional em ambientes com elevada taxa de seleção foi a preocupação central do Simpósio Especial de Pesquisa promovido pelo Journal of Management Studies em 2003, no qual estudos co-evolucionários foram apresentados.

Destes estudos, o trabalho de Rodrigues e Child (2003) trouxe importantes contribuições à teoria co-evolucionária, com destaque para definição clara dos níveis micro, meso e macro de análise, realização empírica de pesquisa longitudinal e estudo do processo de co-evolução em um ambiente altamente institucionalizado, o que não foi abordado por Lewin e Volberda (1999), que deram maior ênfase aos contextos competitivos (o que fica claro no esquema anteriormente apresentado na figura 1). Como contribuição central, o estudo de Rodrigues e Child (2003) avança na teoria da co-evolução, principalmente, ao incorporar a dimensão política no modo como as organizações se transformam e assumem novos formatos.

Com base nas discussões precedentes, parece possível concluir que a realização de pesquisa organizacional - sob a abordagem de múltiplos níveis - torna evidente a impossibilidade de um único paradigma dar conta de explicar as mudanças (de efeitos recursivos múltiplos) ocorridas nos níveis do sistema organizacional.

Desta forma, é preciso buscar argumentos que permitam estudar adequadamente tais níveis de relacionamento e também identificar os paradigmas da teoria organizacional que fornecem as categorias necessárias ao estudo. Neste sentido, a lente da co-evolução, ampliada pelas possibilidades de estudos contemporâneos - como os das organizações em crise e dos processos de reestruturação e seus múltiplos impactos - ganha contornos adicionais, expandindo-se para além dos campos ditos competitivos.

É importante destacar que o campo dos estudos organizacionais precisa avançar em direção a uma visão mais integradora, que considere as dinâmicas macro sociais e econômicas e seus impactos decisivos ocorridos no nível da firma (efeitos em termos de formato, de identidade, de cultura e de processos de aprendizagem). Da mesma forma, a análise das influências inversas - da firma para o macro contexto também deve ser considerada quando o estudo é feito sob um enfoque co-evolucionário. As situações diagnosticadas em um certo espaço temporal devem ser compreendidas a partir de um olhar recursivo, em que relações lineares de causa e efeito cedem espaço para uma perspectiva de influências mútuas, indiretas e circulares.

A abordagem co-evolucionária, somada às demais perspectivas referenciadas neste artigo, demonstra potencial para que tais estudos sejam desenvolvidos a partir dos argumentos que melhor concorram para a compreensão dos fenômenos estudados, quer estejam eles nas instituições, nos custos de

Revista de Gestão e Projetos - GeP, São Paulo, v. 3, n. 2, p 97-115, mai./ago. 2012. 
transação, nas estruturas de governança, nas relações sociais, nos diferentes tipos de economia, nos processos de transição e/ou de reestruturação organizacional, ou nas questões sobre confiança e quebra de confiança nas organizações.

Com tais afirmações, contudo, não se quer propor que o conflito entre teorias rivais não seja oportuno. Na perspectiva de Reed (1999, p. 91), pode-se dizer que é “o confronto entre tradições narrativas rivais, particularmente quando suas tensões internas e contradições ou anomalias estão clara e cruelmente expostas, que fornece o dinamismo intelectual essencial ao redescobrimento e renovação dos estudos organizacionais". Embora as contradições não tenham sido o fio condutor do presente estudo, ainda assim elas se fizeram presentes, já que ficou latente que muitos teóricos propuseram seus argumentos em contraposição às visões ora cristalizadas na teoria organizacional.

Não se pode deixar de destacar, também, a existência de importantes desafios metodológicos que se impõem a todo pesquisador que pretenda fazer estudos co-evolucionários. As dificuldades apresentadas por Lewin e Volberda (1999) - como o acesso a dados em séries temporais, e a escolha de técnicas de análise, por exemplo - podem limitar enormemente o desenvolvimento de estudos na área e é por esta razão que as tentativas bem-sucedidas de pesquisas organizacionais co-evolucionárias devem ser atentamente analisadas pela academia, de modo a permitir o estudo, a consolidação e a validação de apropriadas estratégias metodológicas. Sem esse avanço metodológico, as pesquisas empíricas continuarão escassas e a teoria da co-evolução não realizará seu potencial no campo de estudos organizacionais.

Para finalizar, é com o espírito de ressaltar a necessidade de redescobrimento e de renovação dos estudos organizacionais que foi desenvolvido este estudo. Caberá a cada pesquisador a condução de seus estudos, bem como as escolhas teóricas e metodológicas que poderão favorecer a melhor compreensão das organizações. Tal é o desafio que se apresenta a cada um.

Revista de Gestão e Projetos - GeP, São Paulo, v. 3, n. 2, p 97-115, mai./ago. 2012. 


\section{REFERÊNCIAS}

Coase, Ronald H. The nature of the firm. In: Stigler, J. G.; Boulding, K. E. (eds). Readings in price theory. Homewood : Irwin, 1937.

Dimaggio, Paul J. e Powell, Walter W. The iron cage revisited: institutional isomorphism and collective rationality in organizational fields. In: Powell e Dimaggio. The new institutionalism in organizational analysis. pp. 63-82. Chicago: The University of Chicago Press, 1991.

Granovetter, Mark. Economic action and social structure: the problem of embeddedness. In: Granovetter e Swedberg (ed.s.). The Sociology of Economic Life. Oxford: Westview Press, 1992.

Lewin, Arie Y. e Volberda, Henk W. Prolegomena on Coevolution: a framework for research on strategy and new organizational forms. Organizational Science: v.10, n.5, sept.-oct. 1999, pp.519-534.

Lewin, Arie Y., Long, Chris P. e Carroll, Timothy N. The coevolution of new organizational forms. Organizational Science: v.10, n.5, sept.-oct. 1999, pp.535-550.

Meyer, John W. e Rowan, Brian. Institutionalized organizations: formal structure as myth and ceremony. In: Powell e Dimaggio. The new institutionalism in organizational analysis. pp. 41-62. Chicago: The University of Chicago Press, 1991.

Powell, Walter W. Neither market nor hierarchy: network forms of organization. In: Thompson, G. et al. (ed.s.). Markets, hierarchies and networks: the coordination of social life. London: Sage Publications, 1991.

Reed, Michael. Teorização organizacional: um campo historicamente contestado. In: Cleg, Stewart et al. Handbook de estudos organizacionais. v.1. São Paulo: Atlas, 1999.

Rodrigues, Suzana e Child, John. Co-evolution in an institutionalized environment. Journal of Management Studies. V. 40, n.8, dec. 2003, pp.2137-2162.

Scott, W. Richard. Institutions and organizations. London : Sage, 1995.

Simon, Herbert A. Administrative behavior: a study of decision-making process in administrative organization. New York : Macmillan Company, 1948.

Volberda, Henk H. e Lewin, Arie Y. Co-evolucionary dynamics within and between firms: from evolution to co-evolution. Journal of Management Studies. V. 40, n.8, dec. 2003, pp. 2111-2137.

Revista de Gestão e Projetos - GeP, São Paulo, v. 3, n. 2, p 97-115, mai./ago. 2012. 
Williamson, Oliver. The economics of organization: the transaction cost approach. American Journal of Sociology, v. 87, n. 3, pp.549-577, nov. 1981.

. Markets and hierarchies: analysis and antitrust implications. New York : Free Press, 1975.

Data do recebimento do artigo: 19/04/2012

Data do aceite de publicação: 06/06/2012

Revista de Gestão e Projetos - GeP, São Paulo, v. 3, n. 2, p 97-115, mai./ago. 2012. 